\title{
A structured form of abstracts for Spinal Cord
}

For some time I have felt that the present form of abstracts of articles for Spinal Cord is not entirely satisfactory concerning the layout and length.

After discussion in the Society there was an unanimous decision that abstracts should, from now on, be structured.

The plan is that articles submitted for publication in Spinal Cord require to have a Structured Abstract of no more than 250 words set out in the form in use in the British Medical Journal. I am most grateful to Dr Richard Smith, Editor of that journal, for his permission to reproduce the example from the BMJ. This pertains to an article on 'Weight in infancy and prevalence of coronary heart disease in adult life' by CHD Fall et al and is provided as an example:

\footnotetext{
Abstract

Objective To determine whether low birth weight and low weight at 1 year are followed by an increased prevalence of coronary heart disease in adult life.

Design A follow up study of men born during 1920 30 whose birth weights and weights at 1 year were recorded.

Setting Hertfordshire, England.

Subjects 290 men born and still living in East Hertfordshire.
}

Main outcome measure The prevalence of coronary heart disease, define by the Rose/WHO chest pain questionnaire, standard electrocardiographic criteria, or history of coronary artery angioplasty or graft surgery.

Results $42(14 \%)$ men had coronary heart disease. Their mean birth weight, $7.9 \mathrm{lb}(3600 \mathrm{~g})$, was the same as that of the other men. Their mean weight at 1 year, $21.8 \mathrm{lb}(9.9 \mathrm{~kg})$ was $1 \mathrm{lb}(454 \mathrm{~g})$ lower $(95 \%$ confidence interval 0.1 to $1.8, P=0.02)$. Percentages of men with coronary heart disease fell from $27 \%$ in those who weighed $18 \mathrm{lb}(8.2 \mathrm{~kg})$ or less at 1 year to $9 \%$ in those who weighed more than $26 \mathrm{lb}(11.8 \mathrm{~kg})$ ( $P$ value for trend $=0.03)$. This trend occurred in both smokers and non-smokers and within each social class.

Conclusion These findings add to the evidence that coronary heart disease is 'programmed' during early growth.

The advantages of Structured Abstracts are that they are much more meaningful to the reader highlighting in a concise form the main vital aspects of the scientific article.

Phillip Harris Editor 